\title{
A
}

Acta HealthMedica

Volume: 2, Issue: 1, January-March 2017, Pages: 147, DOI: http://dx.doi.org/10.19082/ah147

\section{APPLYING TELEMEDICINE IN REHABILITATION AND TREATMENT OF PARKINSON'S DISEASE}

\author{
Mostafa Langarizadeh ${ }^{1}$, Fateme Moghbeli $^{2}$, Abbas Sheikhtaheri ${ }^{3}$
}

1: Assisstant Professor of medical informatics, Department of Health Information Management, School of Health Management and Information Sciences, Iran University of Medical Sciences, Tehran, Iran.

2*: Ph.D. Student in medical informatics, Department of Health Information Management, School of Health Management and Information Sciences, Iran University of Medical Sciences, Tehran, Iran.

3: Assisstant Professor of health information management, Department of Health Information Management, School of Health Management and Information Sciences, Iran University of Medical Sciences, Tehran, Iran.

Correspondence:

Fateme Moghbeli, Tel: +989153094230, E-mail: fateme.moghbeli@gmail.com

\section{TYPE OF ARTICLE: CONFERENCE ABSTRACT}

\begin{abstract}
Introduction: Applying technology increases telemedicine usage in rehabilitation and treatment. Parkinson's is the second common disease in neurology problems. Elder people face this problem more than the young. Fast diagnosis can help patients to heal better and easier, and telemedicine can help improve access. We are going to characterize different aspects of telemedicine in rehabilitation of Parkinson's disease, especially wearable devices and sensors usage.

Methods: The required data in the present systematic research were derived from published electronic sources and credible academic articles published in such databases as PubMed, Scopus and Science Direct in the past five years. The following keywords were searched for, in separation and in combination: telemedicine, tele-care, telehealth, Parkinson's disease. Finally, 60 articles were found that met our criteria. Only 30\% of them reported wearable devices and sensors and their use in tele-Parkinson.

Results: The common use of tele-Parkinson is transferring and receiving information by wearing devices, sensors and mobile applications (reported $30 \%$ of chosen articles). These devices can achieve physical and emotional data and use them for choosing doze of patient's drugs. Thus, using tele-Parkinson can increase quality of life and access to treatment.

Conclusion: For implementing tele-Parkinson, wearing devices and sensors are needed. Thus, it can decrease cost and improve good and fast treatment. As a recommendation, it is better to classify technologies that were used for tele-Parkinson and discuss all of them; in this paper, we simply classified them and explained wearing devices, sensors, and mobile applications.

KEYWORDS: Telemedicine, Tele-care, Tele-health, Parkinson's disease, Wearable device
\end{abstract}

\footnotetext{
Abstracts of First National Congress of Medical Informatics, Mashhad, Iran, February 2017

(C) 2017 The Authors. This is an open access article under the terms of the Creative Commons Attribution-NonCommercialNoDerivs License, which permits use and distribution in any medium, provided the original work is properly cited, the use is non-commercial and no modifications or adaptations are made.
} 